\title{
Environmental performance assessment of the use stage of buildings using dynamic high-resolution energy consumption and data on grid composition
}

Karl, Asger Alexander Wendt; Maslesa, Esmir; Birkved, Morten

Published in:

Building and Environment

Link to article, DOI:

10.1016/j.buildenv.2018.09.042

Publication date:

2019

Document Version

Peer reviewed version

Link back to DTU Orbit

Citation $(A P A)$ :

Karl, A. A. W., Maslesa, E., \& Birkved, M. (2019). Environmental performance assessment of the use stage of buildings using dynamic high-resolution energy consumption and data on grid composition. Building and Environment, 147, 97-107. https://doi.org/10.1016/j.buildenv.2018.09.042

\section{General rights}

Copyright and moral rights for the publications made accessible in the public portal are retained by the authors and/or other copyright owners and it is a condition of accessing publications that users recognise and abide by the legal requirements associated with these rights.

- Users may download and print one copy of any publication from the public portal for the purpose of private study or research.

- You may not further distribute the material or use it for any profit-making activity or commercial gain

- You may freely distribute the URL identifying the publication in the public portal 


\title{
Environmental performance assessment of the use stage of buildings using dynamic high-resolution energy consumption and data on grid \\ composition
}

\author{
Asger Alexander Wendt Karl, ${ }^{\mathrm{a}, 1}$ Esmir Maslesa, ${ }^{\mathrm{b}}$ Morten Birkved, ${ }^{\mathrm{b}, \mathrm{c}}$ \\ a Technical University of Denmark, Department of Civil Engineering, Lyngby, Denmark \\ ${ }^{\mathrm{b}}$ Technical University of Denmark, Department of Management Engineering, Lyngby, Denmark \\ c SDU Life Cycle Engineering, Department of Chemical Engineering, Biotechnology and Environmental Technology, \\ University of Southern Denmark, Odense, Denmark \\ 1) Corresponding author: email: AsgerWKarl@gmail.com
}

\begin{abstract}
During the use stage of buildings, their consumption of electricity has proved to influence considerably their environmental performance. The impacts associated with using electricity are directly related to the electricity grid that delivers the power and hence are also closely associated with the impacts induced by the production of each kWh delivered to the grid. Life-cycle assessment (LCA) usually does not account for the variations in the energy sources that supply an electricity grid every day, month and year. This study addresses the dynamic nature of electricity grids and accounts for the source variations in electricity production using electricity grid data at high temporal resolutions. The study compares inventory data on electricity grid composition at hourly, daily and monthly resolutions with the conventional yearly average grid compositions from the ecoinvent database. The high-resolution electricity grid inventory data are subsequently paired with data sets for electricity consumption by buildings with matching resolutions in order to quantify the differences in the environmental performance of buildings resulting from the application of temporally high-resolution grid data. Finally, environmental building performance (EBP) calculated using high-resolution grids is compared to EBPs generated from conventional data resolutions.
\end{abstract}


The results indicate that the contribution to global warming potential is closely related to the data resolution of the grid composition and that the EBP may be overestimated by up to a factor of two when compared with conventional grid inventory data with yearly (i.e. low) data resolutions.

Keywords: dynamic LCA, environmental performance, energy, building, consumption data

\section{Introduction}

\subsection{Dependence on electricity}

Electricity is an essential part of modern society. Our dependence on electricity has its origin in the industrialization of the western world, where the large-scale introduction of electricity accelerated global industrialization by providing "easily available, cheap, and reliable energy from non-renewable fossil fuels, such as coal, oil, and natural gas" [1][2]. Fossil fuels are still a major component of the global energy mix, with larger shares in emerging and developing economies.

The energy crisis of 1973 left Denmark and other Nordic countries in a situation that forced them to rethink their national energy supplies not only by moving away from being solely reliant upon fossil fuels, but also by reducing their dependence on the energy resources of foreign countries. This resulted in an ambition to develop renewable domestic energy sources suitable for the political and geographical situation of each Nordic country. In Denmark this led to the large-scale construction of infrastructure to harness wind power, while Norway decided in favour of hydro-power, and Sweden and Finland opted for biomass from their vast forests, which they combined with nuclear power. Today all these countries still import energy, but at a much lower scale than in the 1970s, and mainly from neighbouring countries.

Current opinion globally is that it is not enough for a country to meet its total energy demand solely by replacing non-renewable energy sources with renewable ones [2]. It is also necessary to reduce global energy consumption drastically, thus countering the misconception that humanity's potential to produce is limitless [3]. 
In Denmark, total energy consumption was 744 PJ in 2017, of which electricity consumption represented $122.5 \mathrm{PJ}$ or around $16.5 \%$ [4]. Figure 1 shows the distribution of total electricity consumption in seven selected sectors in Denmark. The office buildings assessed in this study fall under the category "public service" buildings, which in 2017 consumed 8\% of Denmark's total electricity consumption.

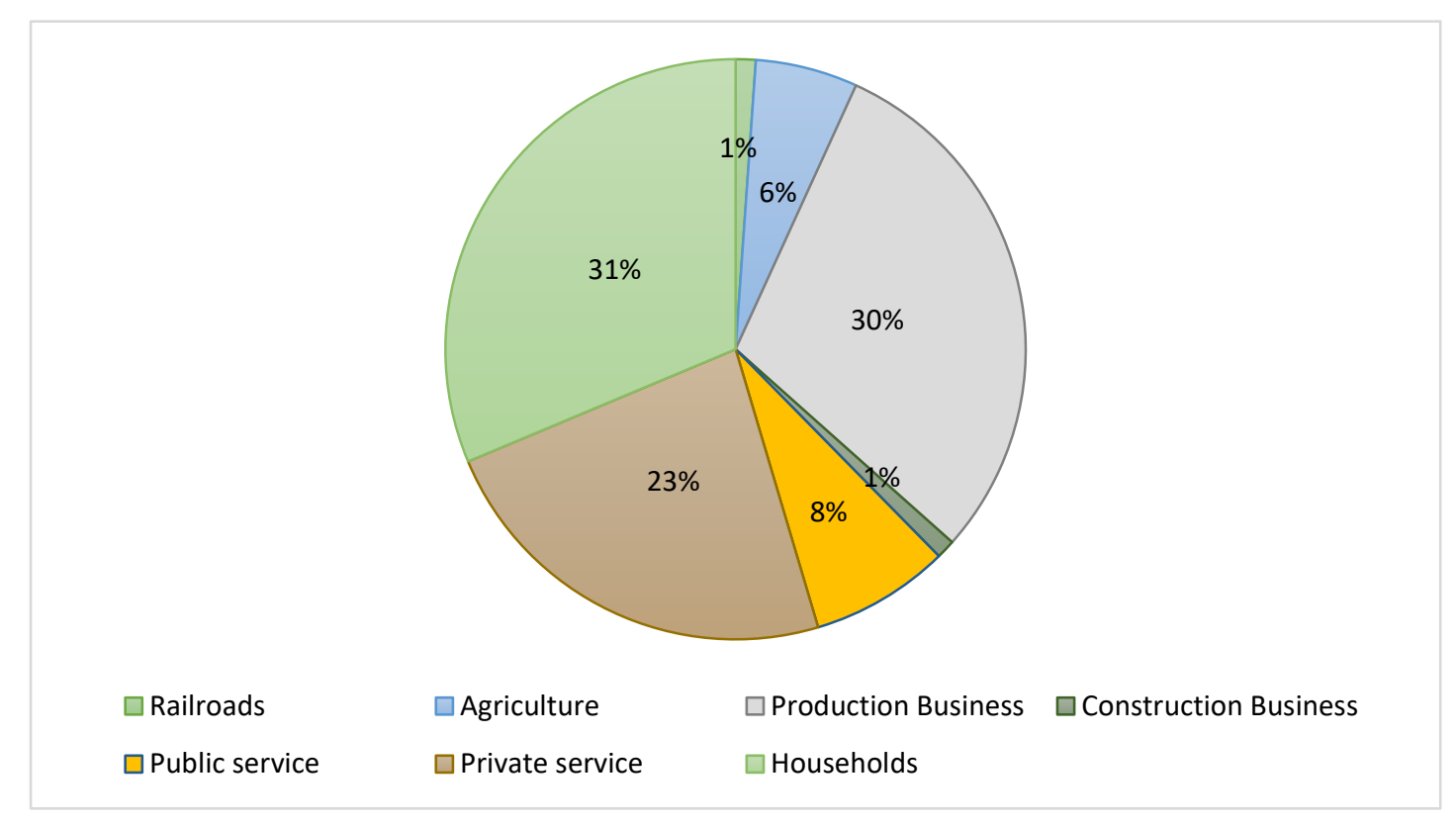

Figure 1: Distribution of electricity consumption in Denmark in 2017.

\subsection{EBP optimization through LCA}

Life-cycle assessment (LCA) is often used to gain understanding of the environmental impacts associated with the manufacture or maintenance of a given service, product or system. It is common to perform an LCA on a building to assess the impacts of all the stages in the life-cycle of a building [5][6]. According to EN 15978 [7], the building life-cycle covers four stages: product, construction, use and end of life. The use stage of a building is its operational and maintenance period and includes operational energy consumption.

In the total life-time of conventional buildings, it is the use stage that has most of the negative environmental impacts [3]. In EBP assessments of various building types (residential, commercial, agricultural etc.), the 
impacts induced during the use stage generally play a predominant role. Earlier research showed that the use stage may represent as much as $90 \%$ of the aggregated impacts of buildings [5][8].

In the use stage, the main contributor to the overall environmental impact is energy consumption [9]. Since energy consumption plays such a crucial role in the EBP, it is clearly essential that quantifying the environmental impacts induced by energy consumption is as representative as possible.

Currently, when it comes to the EBP of buildings, the usual method is to apply a static power grid that does not vary throughout the lifetime of the modelled building system, combined with yearly estimates of annual average power consumption [10]. The combination of these two parameters allows the environmental impacts resulting from the building's energy consumption to be quantified[11].

Given how important energy consumption is for the EBP, and as Sohn et al. have demonstrated [12], using only static power grids and relying on yearly averages may not be the correct way to present the actual performance of the building in question. However, the neglect of temporal differentiation is one of the most significant drawbacks of LCA, one that has been addressed several times in published research on it [13][15]. Furthermore, Anand and Amor [16] argue that some of the gaps in the LCAs of buildings can be covered by incorporating more dynamic aspects for tracking the potential changes over a long period. Also, Roux et al. [17] argue that current LCA practice based on a documented reference year should be replaced by the temporal variability of electricity production within a year. For example, they found that the discrepancy between the annual and hourly impact results could be over $40 \%$ for some indicators. This article therefore examines the LCA application of high-resolution dynamic energy data in office buildings, taking into consideration parameters like temporal variations in the composition of the power grid, as well as the building's location, age and size.

The aim of the present article is thus to quantify the importance of accounting for the variations in electricity production throughout the year. This task is accomplished by quantifying the environmental impacts induced by electricity consumption in office buildings with an hourly data resolution to account for changes in consumption and grid composition simultaneously. The purpose is to quantify the variations in the impacts 
per $\mathrm{kWh}$ consumed throughout the year and to combine these time-dependent impacts with actual electricity consumption data in order to obtain the most accurate EBP assessment of the building's use stage as possible [18].

The energy grid data and energy consumption data for buildings are compared at different resolution scales in order to analyse the differences in the EBPs so that recommendations can be made as to which method is most pertinent.

Lastly, the high-resolution energy calculations are compared with a standard, static system assessment approach, where, in respect of energy consumption, the EBPs are calculated using the standard method, and the degree to which these results differ is quantified.

\subsection{Dynamic LCA}

As a concept, dynamic modelling in LCAs has emerged over the past few years, the intention being to counteract some of the shortcomings inherent in traditional, static LCAs. Where traditional LCA practices are more rigid in their structure, dynamic system models and/or system inventories allow for the inclusion of parameters that change throughout the temporal scope of the LCA, thus reflecting more accurately the reallife circumstances of the system being assessed [19].

Dynamic system modelling often includes temporal variations in unit processes, and in some cases this consideration leads to results that differ from their static counterparts [12][14].

Dynamic LCAs differ from conventional ones through the inclusion of temporal and spatial variations in the system modelling [20]: just as the temporal considerations have major implications for the accuracy and representativeness of the LCA as a whole, so can spatial variations influence the results of an LCA and thus the conclusions drawn from it. With regard to building LCAs, a key aspect of the overarching results is occupant behaviour, which, over the course of a buildings' long lifespan, has great potential to affect the EBP [15][21]. 
Naturally there are limitations to the application of dynamic modelling practices in LCAs. While the temporal considerations potentially yield significantly greater accuracy in the impact modelling, they also necessitate vast amounts of data. In most cases the data required to perform the LCAs at the highest resolutions (i.e. temporally and spatially dynamic) are not available, limiting their representativeness [20]. In scenarios in which the data necessary to perform dynamic LCAs are available, these data can relieve the uncertainties from the static product system models that might otherwise arise.

Even though dynamic LCA practices have already been proved to yield informative results, the full extent of their implementation is not yet known, and the methods are still relatively new. The application of dynamic frameworks has the potential for far-reaching implications in the field of LCA, and such frameworks are continually being developed further. Recent studies have evaluated the applications of dynamic characterization, showing that the different impact categories do not react identically to temporal dynamic frameworks [22]. In the sensitivity analysis presented by Shimako et al. [22], it is shown that, for both climateand toxicity-related impacts, the temporal considerations influence the results when compared to static systems. Furthermore, Shimako et al. [22] show that the time increment (i.e. the temporal resolution) one choses has the greatest effects on the toxicity-related impacts, while the climate change-related impacts are not affected by the temporal resolution. This observation is assumed to be related to the time scale of the related impacts. That is, toxicity-related impacts have a maximum time-scale of months or a few years, while climate change-related impacts have time scales of decades or even several centuries, depending on the method of characterization.

As shown above, the implementation of dynamic LCAs has proved to be of major significance for projects where such an approach to assessment is feasible data-wise. Applying a dynamic framework therefore has the potential to influence the final results of an LCA significantly. However, the full implications of the approach are as yet unknown, and the practices are continually being expanded upon. 


\subsection{Electricity grids}

When considering temporal variations within the LCA framework, the main objective is to divide the lifetime of the system into (smaller) time steps, for which, for example, the materials and energy supplied can also be divided. When assessing the energy consumption of a building, this approach provides a more detailed impact assessment framework and is an obvious improvement over conventional static system models, due simply to the much finer data resolutions and hence the number of variations that can be taken into consideration. While it is important to account for the timeframe of the energy consumption, it is potentially even more important to account for the variations in electricity grid composition during the same period [23][24]. Thus, when constructing an inventory for, for example, energy consumption, it is no longer "just" a question of quantifying that consumption, but also of resolving it over time and determining when the energy is consumed, thereby adding an additional dimension to the inventory analysis. Depending on the national context and timeframe in question, the composition of the electricity grid has the potential to fluctuate considerably, and the environmental impacts caused by its production can change in an unsystematic manner, meaning that the impacts per unit of energy consumed also may change in an unsystematic manner [25][26].

A national electricity grid is a complex infrastructure, with numerous processes and components to consider when assessing the environmental impacts induced by electricity production. The major factors to consider are the extraction of materials for purposes of production, the emissions generated by using these materials, the construction and maintenance of grid infrastructure, and the losses caused by transmission and transformation [27]. All of these factors must be taken into account when making recommendations for changes to the grid. Given also the scale of the system and the desire for affordable energy, it can be difficult to find the best solution [28].

Denmark is in a unique situation when it comes to global ambitions for the future of renewable energy, as these have also been Denmark's ambitions for many years, and as a result much of the required infrastructure is already in place. However, the Danish power grid still relies on non-renewable sources, as well as imports 
of energy from countries that rely heavily on non-renewable energy sources. Nonetheless, future plans for a Danish power grid seek to make the grid completely independent of international sources of power and $100 \%$ reliant on renewable energy. The key component of the 2050 renewable-energy grid plan is the flexibility of the grid [2]. The goal is to shape the infrastructure so as to accommodate short- and long-term changes in renewable energy sources in order to utilize the energy being produced fully, combined with an overall decrease in energy demand.

As such, granting the use stage and hence energy consumption a more prominent role in LCAs of building is only logical, and it has the potential to play a major part in the development of the dynamic framework of building LCAs in the future.

\subsection{Dynamic high-resolution data}

Dynamic high-resolution data are data used in combinations of dynamic modelling practices, which divide traditional data into many smaller components, allowing for an increase in the number of data points available to portray the system to a much higher degree of detail and to identify tendencies that would not be visible otherwise.

With respect to this study, high-resolution data are included by dividing the year into months, days and hours, instead of using just one yearly average representing a single data point aggregating 8,760 hourly data points into one single data point or aggregating 365 daily data points into one single data point. Depending on the approach to aggregation, it is assumed that a simplification reducing the data resolution by three to four orders of magnitude can be regarded as representative.

Coupling dynamic inventory analysis with dynamic system modelling, as presented here, has the potential to increase the representativeness of an LCA substantially and thus to reduce the uncertainties that are otherwise inherent in similar assessments that do not account for changes throughout the year. Especially in relation to assessments of the absolute EBP, as presented by, for example, Brejnrod et al. [3], the 
representativeness of both the inventory and the system model will play an important role in achieving the overall validity of the results obtained.

\section{Methods}

\subsection{Data collection}

The study is based on high-resolution inventory data sets on the energy source composition of Denmark's national electricity grid and building-specific electricity consumption data on eighteen office buildings located in eastern and western Denmark. Both data sets have an hourly resolution covering the whole of 2017.

National electricity grid data are provided by Energinet, Denmark's national transmission system operator for electricity and natural gas [25]. These data are supplemented by further data on energy production in Denmark from the Danish Energy Agency [29]. The purpose of drawing supplementary data from the Danish Energy Agency was to increase the resolution of the data for both local and central power production by using the data to enable both forms of power production to be distinguished according to their basic sources (biomass, biogas, natural gas, etc.).

The Danish Building and Property Agency (Bygningsstyrelsen or BYGST) provided specific electricity consumption data for eighteen state-owned office buildings, matching the data format and resolution of the electricity grid data. The eighteen office buildings selected for the study are equally distributed between eastern and western Denmark, with nine in each part of the country. More details on all eighteen buildings are provided in Table 6 of the supporting information (SI). One building (W2) lacked hourly and daily data resolutions and was therefore left out of the subsequent analysis.

The buildings have been anonymized and are denoted by a letter and a number only. This is due to the sensitive nature of data on electricity consumption, which are protected by Danish law. The consumption data were provided through a special legal agreement with BYGST. 


\subsection{Regionalization of the energy data}

The data from Energinet are intrinsically divided into eastern and western Denmark, the dividing line being the Great Belt, that is, the sea between the islands of Zealand and Funen. The reason for this regional split is the practice of transferring energy between eastern and western Denmark, especially from west to east. While overall imports of fossil fuels for electricity production have declined steadily since the 1970s, both eastern and western Denmark still import a considerable proportion of the energy they consume. The east primarily imports energy from the other Nordic countries (and to some degree from western Denmark), the west mainly from neighbours on the European continent, especially Germany.

\subsection{Reference impact values (openLCA \& ecoinvent 3.3)}

Data on the national electricity grid obtained from Energinet and the Danish Energy Agency divides the energy mixture into the following energy sources: oil, coal, waste, solar, offshore wind, onshore wind, natural gas, biomass, biogas, exchange with Nordic countries and exchange with the European continent.

Using the openLCA software [30] and the ecoinvent 3.3 inventory database [31] in combination with the characterization model and impact categories from ReCiPe ver. 1.11 - hierarchical perspective [32], the reference impacts for the production of $1 \mathrm{kWh}$ of each energy source were calculated, both for midpoint impact potentials and endpoint scores using ReCiPe $(\mathrm{H})$.

The total impacts per kWh were calculated using the energy source-specific unit impacts (i.e. source-specific impact per kWh produced) for each of the energy sources in the Danish grid. Combining the energy sourcespecific unit impacts with the determined composition of the energy grid, the impact for each hour of the calendar year 2017 for each impact category was calculated by multiplying the relative source contributions per hour with the corresponding energy source-specific unit impacts.

In addition, the loss in energy due to either transformation or transmission was determined from the differences in gross and net electricity production. These energy source-specific loss factors were later 
multiplied by the electricity consumption of the buildings to improve the precision of the actual power grid data.

The same method was used to determine the average impact potentials of every kWh per day and per month. This procedure would later facilitate the quantification of the differences in the overall EBPs when using varying data resolution in the quantification of the energy grid and energy consumption combined impacts. The energy consumption-induced impacts at the midpoint and endpoint levels of the individual buildings were calculated hourly, daily and monthly using the existing national-grid process for Denmark in the ecoinvent database in combination with the measurements of energy consumption. The purpose of this calculation was to establish data resolution-specific reference points allowing the building-specific impact changes to be quantified by relying on conventional ecoinvent inventory data or actual high-resolution energy grid/consumption data. The goal of comparing the two different ways of quantifying the EBP is not only to evaluate whether higher energy grid/consumption data resolution can have a significant influence on the overarching EBP results, but also to determine which level of data resolution is most appropriate.

\section{Results}

\subsection{Energy grid results}

Figure 2 presents the results obtained from the initial calculations of the reference impact for global warming potential (GWP) of the various energy sources for Denmark's energy production processes. The figure shows the GWP induced by the production of one kWh for each energy source. The total contributions from each energy source within the various categories are presented in Table 1 of Appendix SI-C. These energy sourcespecific unit reference impacts constitute the foundation for later calculations of the impact potentials of every kWh produced per hour, per day and per month. 


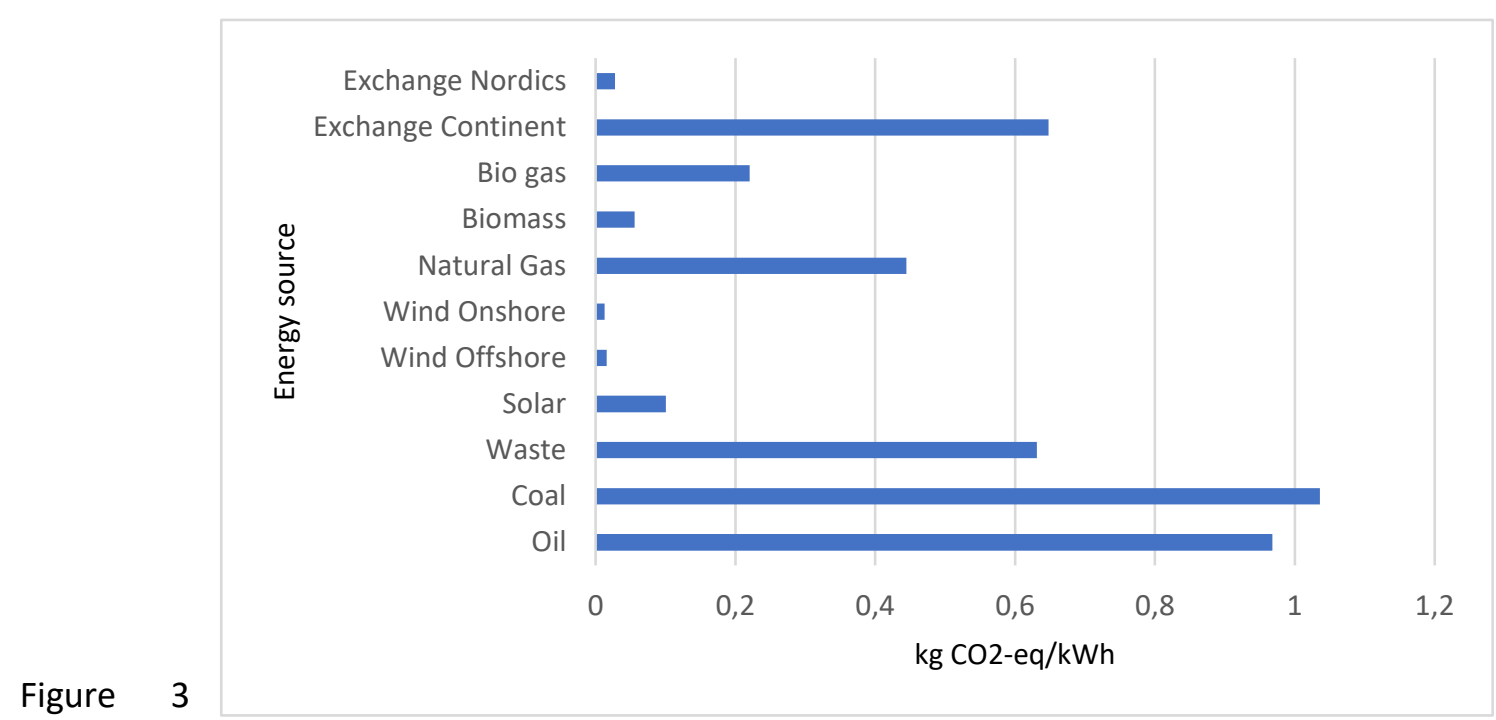

presents

Figure 2. Source-specific GWP/kWh [kg CO2-eq/ $\mathrm{kWh}]$ showing the contribution to the GWP for each of the energy sources comprising the Danish electricity grid as calculated from openLCA.

the calculated GWP impacts per kWh based on the hourly grid resolution in order to reflect the monthly average variation throughout the year. The yearly averages were calculated from the electricity grid impact results, and the deviations from the averages are displayed in percentages.

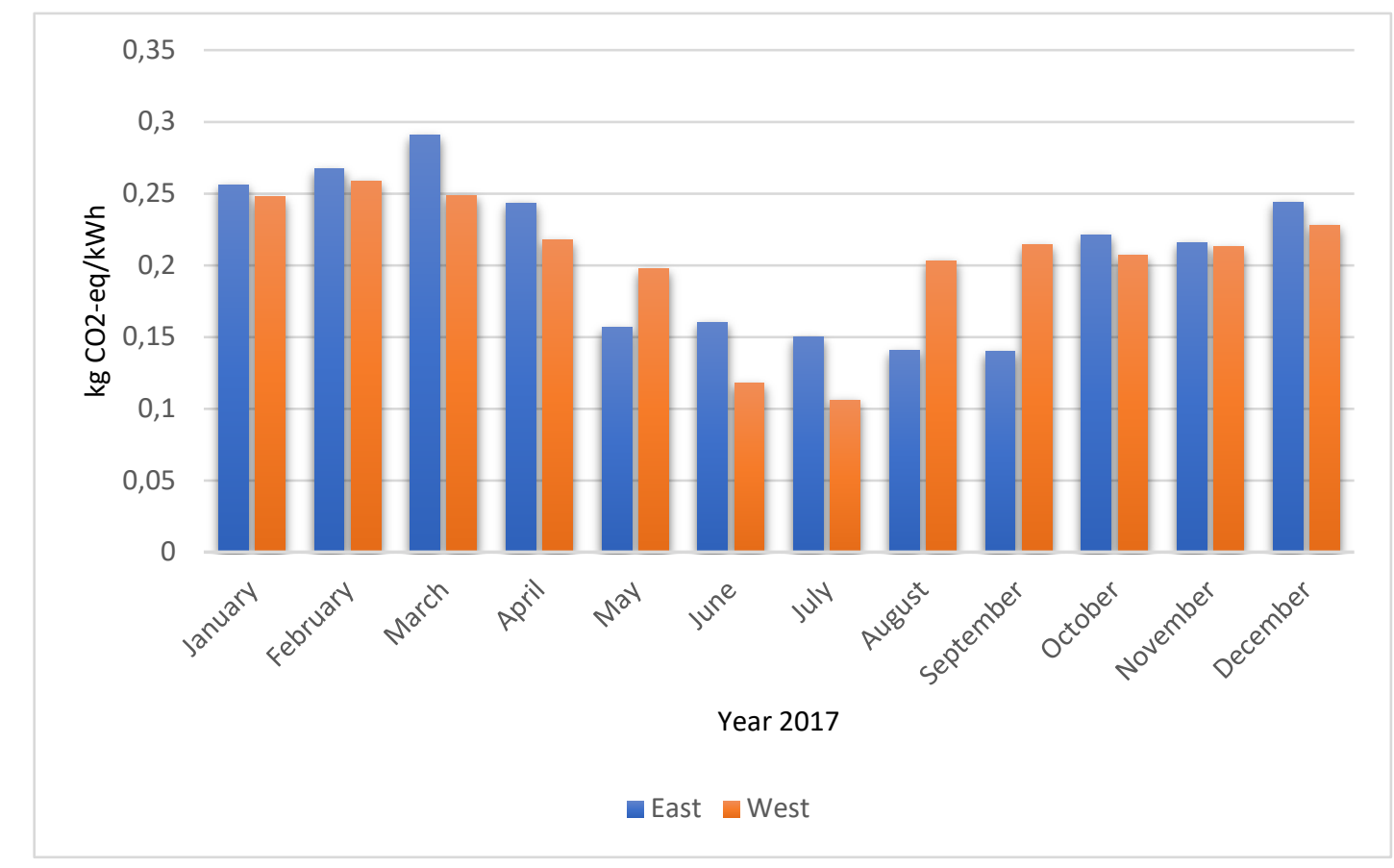

Figure 3

Figure 3. Monthly average GWP/kWh for eastern and western Denmark. shows a significant difference in the GWP per kWh for western and eastern Denmark, depending on the month in which electricity production takes place. The corresponding data, that is, the endpoint results, are provided 
in section 3.1 of the SI. The scores for the remaining impact categories can also be found in Appendix SI-C, showing the substantial changes that occur on a monthly basis. For instance, in western Denmark, agricultural land occupation scores are $156.3 \%$ of the yearly average in January, but only $384 \%$ in June for the same amount of electricity produced. The eastern grid shows the same trends. Table 1 summarizes the results of these impact score variations presented as monthly average deviations from the yearly average. Table 1 further shows that in western Denmark the deviation in impact categories for January is $11.8 \%$ higher than the yearly average, while equivalent production in July on average induces $33.6 \%$ less impacts.

Table 1. Average monthly deviations of all midpoint impacts from the yearly average for western and eastern Denmark. See Table 2, Appendix SI-C, for further information.

\begin{tabular}{lll}
\hline Average deviation in impact categories & West & East \\
\hline January & $111.8 \%$ & $109.3 \%$ \\
\hline February & $116.7 \%$ & $114.6 \%$ \\
\hline March & $114.8 \%$ & $127.8 \%$ \\
\hline April & $104.8 \%$ & $114.6 \%$ \\
\hline May & $98.4 \%$ & $86.1 \%$ \\
\hline June & $70.8 \%$ & $89.4 \%$ \\
\hline July & $66.4 \%$ & $81.2 \%$ \\
\hline August & $102.2 \%$ & $78.9 \%$ \\
\hline September & $102.8 \%$ & $74.5 \%$ \\
\hline October & $101.6 \%$ & $109.6 \%$ \\
\hline November & $102.5 \%$ & $100.8 \%$ \\
\hline December & $107.1 \%$ & $113.3 \%$ \\
\hline
\end{tabular}

The general tendency in western Denmark is that any power produced from May to July will have a lower impact compared to the remaining months when calculating the average across all categories. This is caused by variations in the composition of the electrical grid between these and the remaining months. For the eastern Danish grid, this also includes August and September. However, when looking at a specific singleimpact category, the opposite may be true in some cases. For instance, electricity produced during these five 
months in the west will have a larger impact in terms of water depletion than in other months due to the water depletion related to solar power production, as highlighted in Table 2 of Appendix SI-C. Table 1 in the SI shows the same results for the eastern grid.

Figures $4 \mathrm{~A}$ and $4 \mathrm{~B}$ present the monthly impact deviation from the yearly averages for electricity production and the associated global warming potential in western and eastern Denmark calculated on the basis of an hourly grid-composition data set. The figures show that the months with lower impacts per kWh also have lower overall energy production, with the exceptions of August and September in western Denmark. August and September have lower electricity production than the yearly average, while also inducing greater impacts per kWh than the yearly average. In eastern Denmark the same pattern is not observed, and all the months with lower electricity production induce fewer impacts per kWh electricity produced. The monthly deviations for the remaining impact categories are given in the Appendix to the SI. 

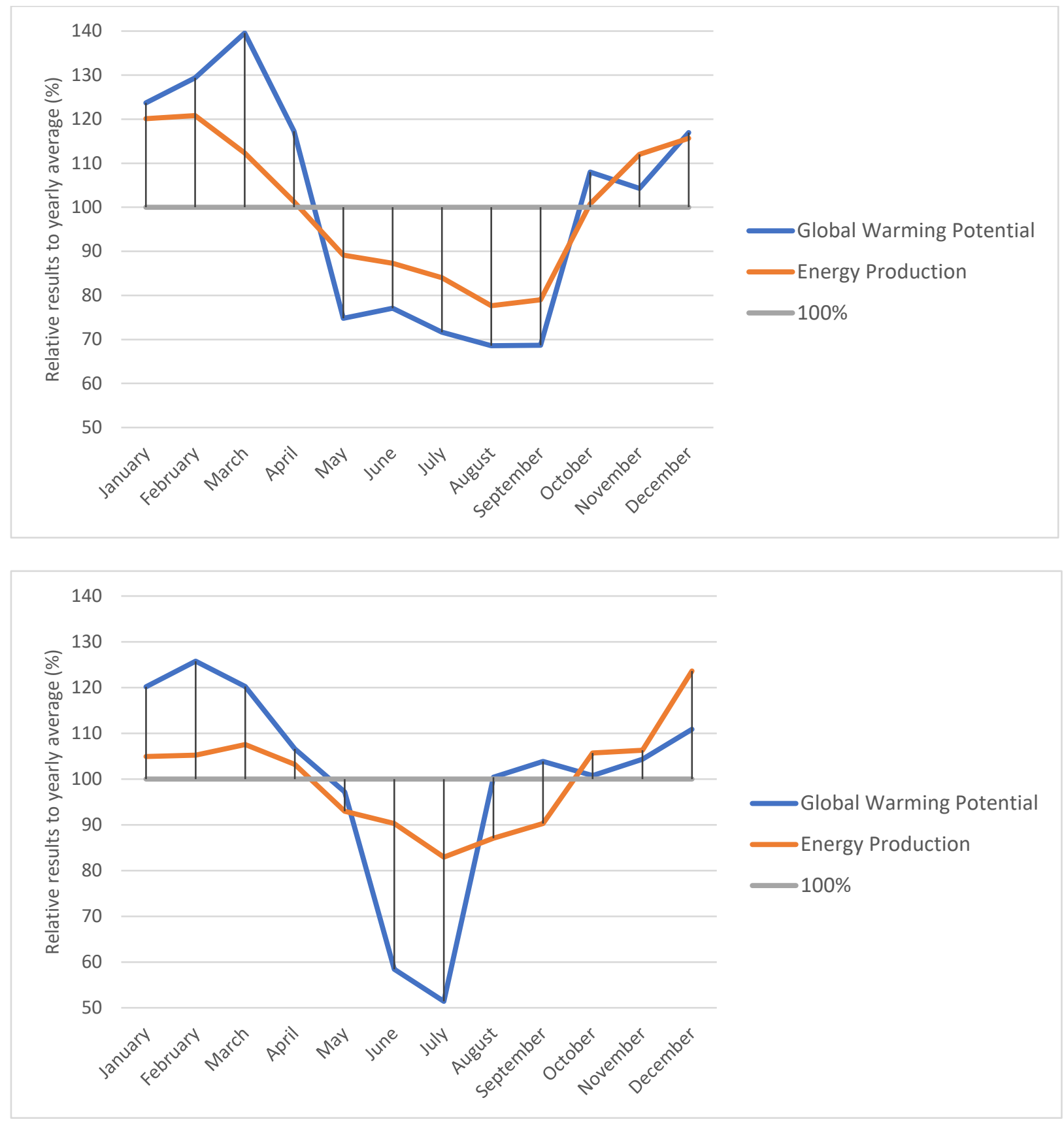

Figure 4A-4B. Deviation from average monthly electricity production and global warming potential per kWh. 4A: eastern Denmark (upper graph); 4B: western Denmark (lower graph).

Apart from August and September, the general trend in the west follows an increase in induced impact per kWh in months when the demand for electricity is high. This is caused by the current limitations in Denmark's capacity to produce energy from sources that have less impact. 
The production of electricity from renewables in Denmark - mainly wind and solar power - currently has three main disadvantages. First, the amount of energy produced by these sources is highly dependent on weather conditions: if no wind is blowing, or if it is cloudy, production is limited. Secondly, we do not yet have the ability to meet the total energy demand during periods of peak demand solely from renewable sources and are therefore dependent on secondary (adjustable) energy sources at these times. Lastly, we have not yet developed efficient ways to store excess energy harnessed from renewable sources, meaning that any such over-production of electricity is wasted when produced at times of low demand. These factors mean that renewable energy sources are not entirely reliable in their current state.

Figure 5 shows the contribution of each electricity source to the national production of electricity for the months of June and December for both eastern and western Denmark. In all four cases the local level of power production serves as a baseline that does not vary greatly on a daily basis, while other sources, such as wind, displayed in green and purple, fluctuate notably. For times when wind production is low, electricity production is supplemented primarily by imports of energy from other countries or through central power plants.

The difference in electricity produced by central power plants and electric boilers respectively is great and is due primarily to the burning of coal and biomass. Reliance on these sources is on average $778 \%$ (central power plants) and 406\% (electric boilers) higher in December. The substantial disparity between these two months is caused by the combination of higher energy demand during the winter months and the lower potential for renewable energy during this season. 

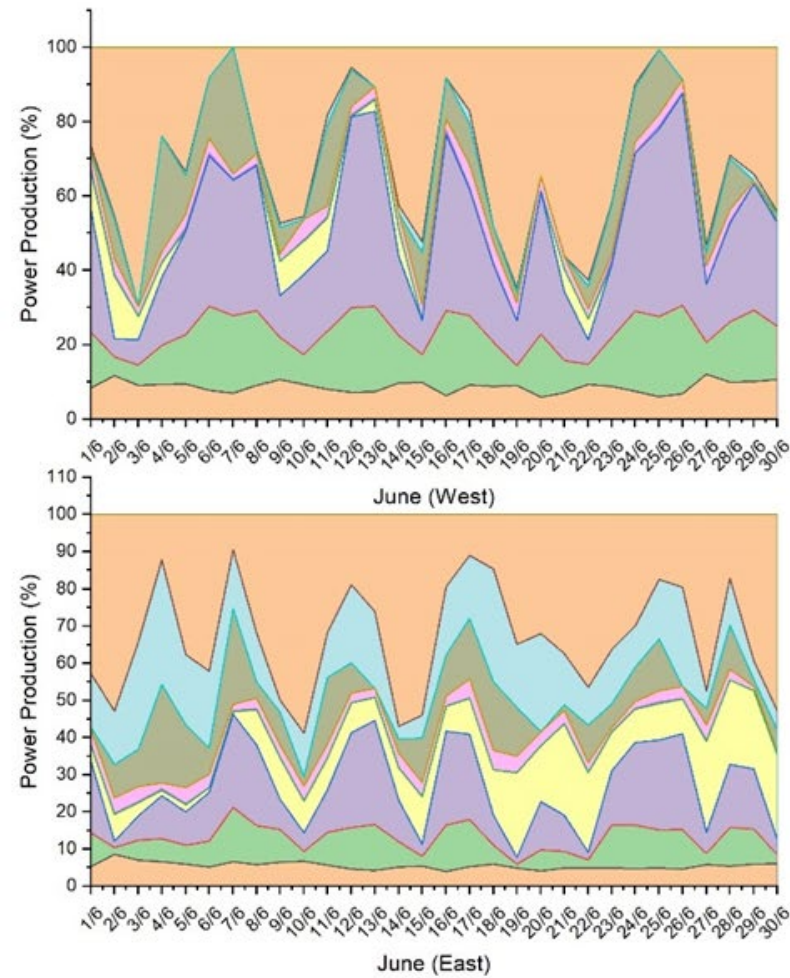

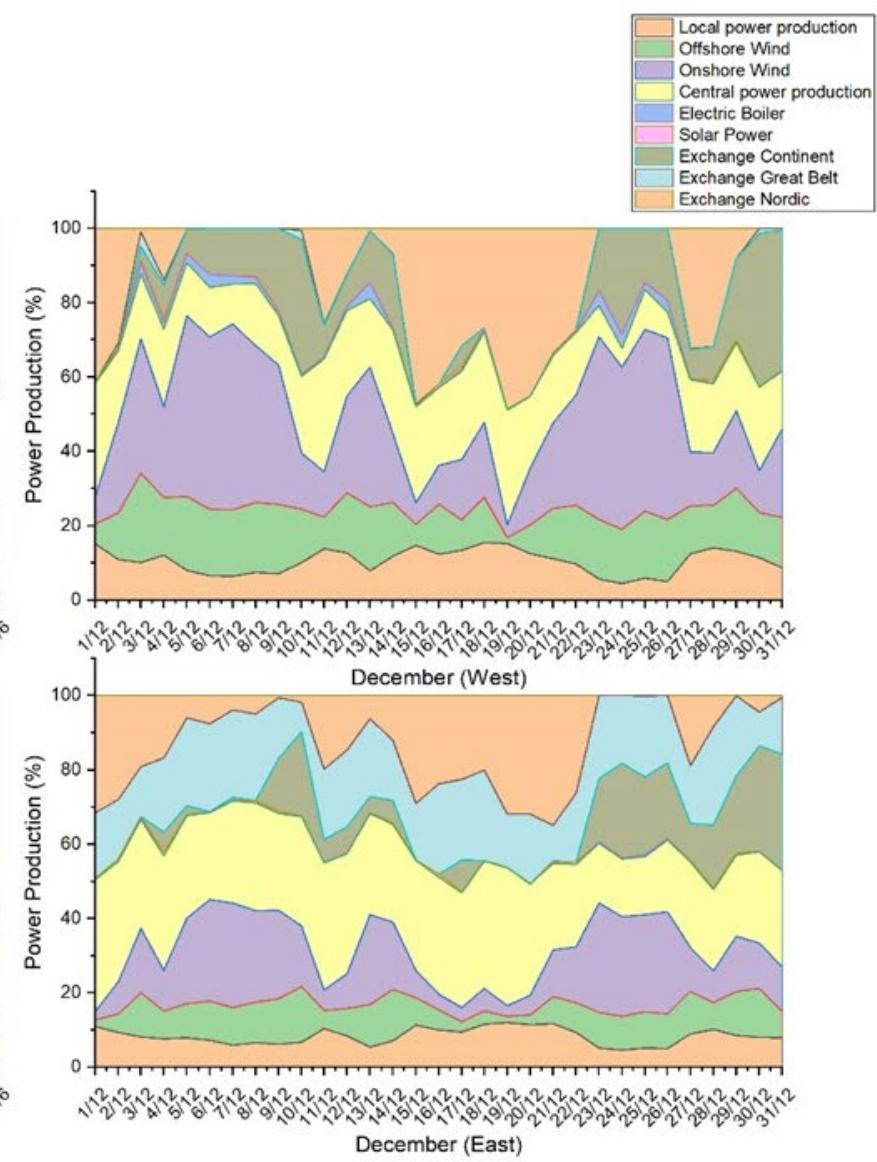

December (East)

Figure 5. Distribution of electricity produced by source for June and December. 5A: June (west); 5B: December (west); 5C: June (east); 5D: December (east).

The effect is a substantial difference in the contributions from individual sources, depending on which time of the year the energy is produced, and leading to an equally substantial difference in the environmental impacts of its production.

Figure 6 charts the development of the Danish electricity grid over the last five years, showing the yearly averages of the contributions of each of the nine main sources comprising the grid. The highlighted data cover only the production of electricity for domestic use and do not take any exported electricity into account. 
Over the years, the Danish power grid has evolved significantly and caused considerable fluctuations in respect of some of its sources. It should also be noted that 2012 is the reference year for the ecoinvent data, and 2017 the reference year for the electricity consumption data and grid compositions used in this study.

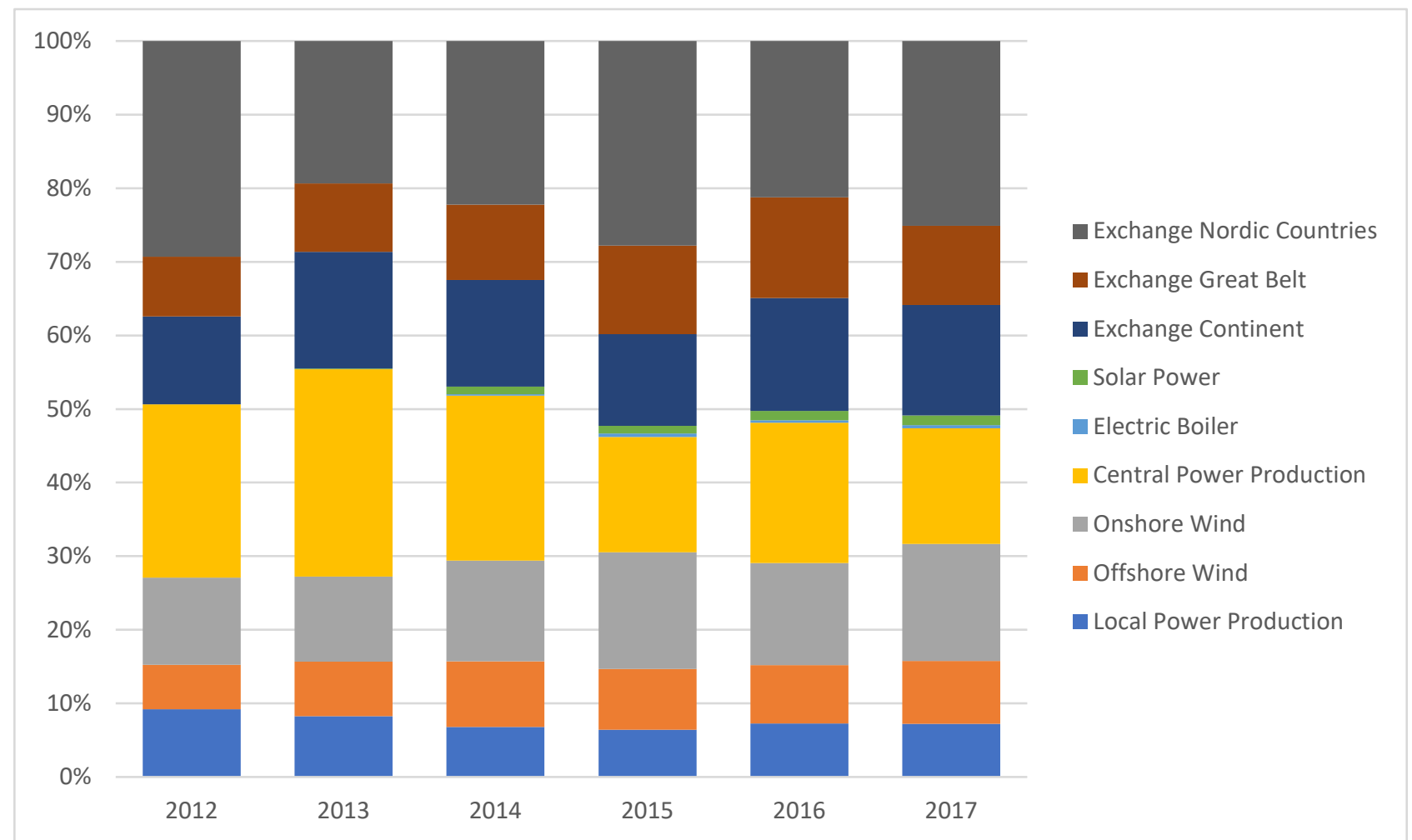

Figure 6. Yearly development of electricity grid from 2012-2017, Denmark as a whole.

From 2012 to 2017 reliance on local power plants decreased from $9.18 \%$ to $7.12 \%$, while the central power plants, which in 2012 supplied $23.52 \%$ of total electricity production, only accounted for $15.72 \%$ of the electricity produced in 2017. Parallel to the decline in the sources mentioned above, there has been a significant increase in the capacity of wind and solar power. Offshore wind power increased from $6 \%$ to $8.5 \%$ along with onshore power, which increased from $11.85 \%$ to $15.86 \%$. Meanwhile, solar power has increased from zero in 2012 to $1.3 \%$ today. 


\subsection{Building-specific results}

The available building-specific energy consumption data give hourly electricity consumption figures for each of the buildings in the study.

Two buildings deviate significantly from the rest. Building W2 only provides aggregated monthly electricity consumption data, thus ruling out hourly comparisons. The second building, W4, is equipped with solar panels that reduce the demand for electricity from the grid during the summer months. As a result building W2 was excluded from the study, while W4 remains included, but with its own electricity production excluded from the calculations, thus utilizing only the data for the electricity delivered to it from the outside. Figure 7 Building electricity-consumption data. Top left: total electricity use. Top right: electricity use per $m^{2}$.
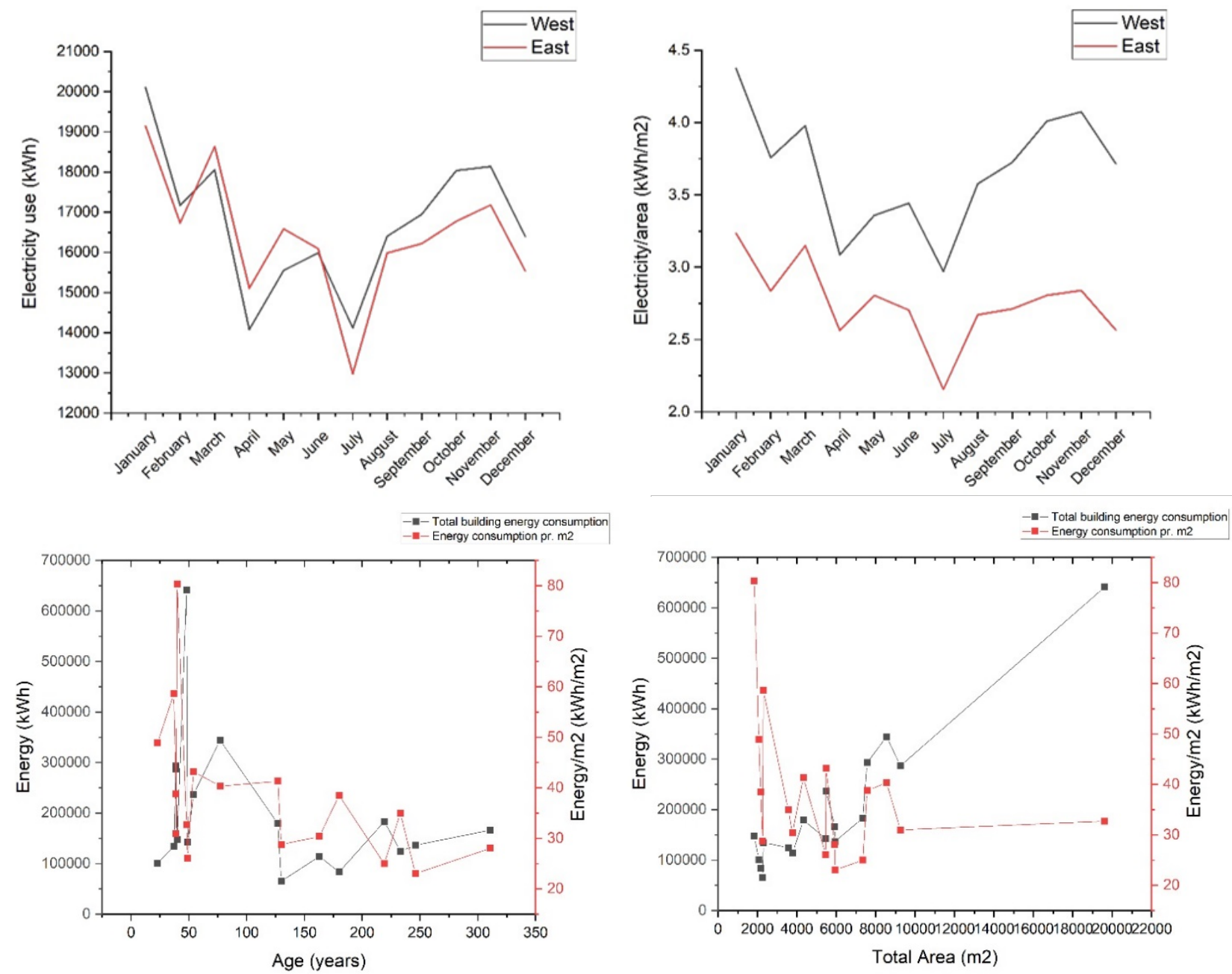

Bottom left: electricity use by building age (years). Bottom right: electricity use by total area $\left(m^{2}\right)$. 
Figure 7 reveals that the larger buildings consume more energy, while the smallest buildings have the highest electricity consumption per $\mathrm{m}^{2}$. When sorting by age, there is no clear trend between building age and total electricity consumption and consumption per $\mathrm{m}^{2}$ except that the newer buildings have generally higher level of consumption, meaning that the area of a given building is a more significant factor in this sort of comparison.

As also shown in Figure 7, the total electricity use of the western buildings is quite similar to that of the eastern buildings and differs only by $2 \%$ on average, while the consumption $/ \mathrm{m}^{2}$ on average is $33.4 \%$ higher on an annual basis for the buildings in western Denmark.

\subsection{Results of combining energy consumption and grid composition}

After collecting the data on energy grids and building-specific electricity consumption, the data are combined

to determine the actual environmental impact induced by electricity consumption in seventeen office buildings. The analysis has two targets: to compare the results for the seventeen buildings obtained using the high-resolution data; and to quantify any application differences between these results and those using conventional averaged data found in ecoinvent.

The comparison is made using both midpoint impact potentials and endpoint scores. Five midpoint categories are highlighted in this article: marine eutrophication, terrestrial acidification, photochemical oxidant formation, climate change and ozone depletion. All midpoint impact potentials are presented in Appendix SI-A. The final comparison between the different data resolutions includes all midpoint and endpoint categories, as presented in section 4.4 .3 of the SI.

\subsubsection{Hourly data resolutions}

The hourly data for power grid composition and electricity consumption have the highest resolutions and as such are considered the most accurate. However, assessments at this data resolution require significantly more data than the daily or monthly systems. Figures $6-8$ in section 4.1 of the SI give the hourly average distributions of both electricity consumption and impact potentials per kWh. Figures 6-8 in section 4.1 also 
show the progression of electricity consumption and production throughout a day based on the total yearly data.

Data with hourly resolutions facilitate the inclusion of the small-scale deviations that occur over a day, such as the significant grid changes in terms of energy sources from day to night, or variations in energy demand between working and non-working hours.

In general, electricity consumption in Denmark is significantly higher during October, November and January, which are also the months with the highest impact potentials per kWh.

Table 2 shows the total midpoint impact potentials for the chosen impact categories. The midpoint impact potentials are on average $37 \%$ higher for buildings located in western Denmark, while the endpoint scores for these buildings have on average $33 \%$ higher impact potentials when compared with buildings in eastern Denmark. The buildings in western Denmark have generally higher impact potentials per $\mathrm{m}^{2}$, as shown in section 3.2 of the SI.

Table 2. Total impact potentials results per $\mathrm{m}^{2}$ for all buildings for the five chosen midpoint categories and from an hourly grid resolution.

\begin{tabular}{|c|c|c|c|c|c|}
\hline Building & $\begin{array}{c}\text { Marine } \\
\text { eutrophication }\end{array}$ & $\begin{array}{c}\text { Terrestrial } \\
\text { acidification }\end{array}$ & $\begin{array}{c}\text { Photochemical } \\
\text { oxidant } \\
\text { formation }\end{array}$ & $\begin{array}{l}\text { Climate } \\
\text { change }\end{array}$ & $\begin{array}{c}\text { Ozone } \\
\text { depletion }\end{array}$ \\
\hline $\mathbf{W 1}$ & $3,00 E-03$ & $4,82 \mathrm{E}-02$ & $3,27 E-02$ & $1,21 \mathrm{E}+01$ & $1,63 \mathrm{E}-06$ \\
\hline W3 & 2,49E-03 & 3,99E-02 & $2,71 \mathrm{E}-02$ & $1,01 \mathrm{E}+01$ & $1,35 \mathrm{E}-06$ \\
\hline W4 & $1,54 \mathrm{E}-03$ & $2,49 E-02$ & $1,69 E-02$ & $6,27 E+00$ & 8,37E-07 \\
\hline W5 & $2,00 E-03$ & $3,10 \mathrm{E}-02$ & $2,11 \mathrm{E}-02$ & $7,97 E+00$ & $1,05 E-06$ \\
\hline W6 & $4,15 E-03$ & $6,43 E-02$ & $4,37 E-02$ & $1,65 E+01$ & $2,19 E-06$ \\
\hline W7 & 1,99E-03 & $3,18 \mathrm{E}-02$ & $2,16 \mathrm{E}-02$ & $8,01 E+00$ & $1,08 \mathrm{E}-06$ \\
\hline W8 & 1,67E-03 & $2,67 E-02$ & $1,81 \mathrm{E}-02$ & $6,71 E+00$ & $9,03 E-07$ \\
\hline W9 & $1,50 \mathrm{E}-03$ & $2,46 \mathrm{E}-02$ & 1,67E-02 & $6,11 \mathrm{E}+00$ & 8,27E-07 \\
\hline E1 & $2,03 E-03$ & 3,69E-02 & $2,32 \mathrm{E}-02$ & $8,97 E+00$ & $1,14 \mathrm{E}-06$ \\
\hline E2 & $1,46 \mathrm{E}-03$ & $2,67 E-02$ & $1,67 \mathrm{E}-02$ & $6,45 E+00$ & $8,25 E-07$ \\
\hline E3 & $1,94 \mathrm{E}-03$ & $3,50 E-02$ & $2,20 E-02$ & $8,57 E+00$ & $1,09 E-06$ \\
\hline
\end{tabular}




\begin{tabular}{cccccc}
\hline E4 & $1,43 \mathrm{E}-03$ & $2,64 \mathrm{E}-02$ & $1,66 \mathrm{E}-02$ & $6,35 \mathrm{E}+00$ & $8,16 \mathrm{E}-07$ \\
\hline E5 & $1,66 \mathrm{E}-03$ & $3,07 \mathrm{E}-02$ & $1,93 \mathrm{E}-02$ & $7,42 \mathrm{E}+00$ & $9,48 \mathrm{E}-07$ \\
\hline E6 & $1,33 \mathrm{E}-03$ & $2,43 \mathrm{E}-02$ & $1,52 \mathrm{E}-02$ & $5,90 \mathrm{E}+00$ & $7,50 \mathrm{E}-07$ \\
\hline E7 & $1,90 \mathrm{E}-03$ & $3,47 \mathrm{E}-02$ & $2,18 \mathrm{E}-02$ & $8,44 \mathrm{E}+00$ & $1,07 \mathrm{E}-06$ \\
\hline E8 & $1,19 \mathrm{E}-03$ & $2,21 \mathrm{E}-02$ & $1,38 \mathrm{E}-02$ & $5,32 \mathrm{E}+00$ & $6,80 \mathrm{E}-07$ \\
\hline E9 & $1,06 \mathrm{E}-03$ & $1,93 \mathrm{E}-02$ & $1,21 \mathrm{E}-02$ & $4,70 \mathrm{E}+00$ & $5,99 \mathrm{E}-07$ \\
\hline Unit & $(\mathrm{kg} \mathrm{N} \mathrm{eq}) / \mathrm{m}^{2}$ & $(\mathrm{~kg} \mathrm{SO} 2 \mathrm{eq}) / \mathrm{m}^{2}$ & $(\mathrm{~kg} \mathrm{NMVOC}) / \mathrm{m}^{2}$ & $(\mathrm{~kg} \mathrm{CO} 2 \mathrm{eq}) / \mathrm{m}^{2}$ & $(\mathrm{~kg} \mathrm{CFC}-11 \mathrm{eq}) / \mathrm{m}^{2}$ \\
\hline
\end{tabular}

\subsubsection{Daily data resolutions}

By using daily data resolutions, some insights are lost by disregarding hourly variations in the energy grid throughout the day and instead assuming every hour of the day to have a uniform grid composition. On the other hand, the daily data resolutions account for the variance between weekdays, which is significant for office buildings, since the difference between weekdays and weekends is considerable. This is because the electricity consumed over the weekend is mainly used for "background" systems, and the amount consumed is hence lower than on weekdays.

The consumption data show substantial falls in energy demand on every weekend or holiday. The average daily energy demand (i.e. baseline) during weekends or holidays is about a third of the average of working days, the weekday variations being highlighted in the daily resolution section 4.2 of the SI. The total average daily deviations in electricity consumption are found in the daily grid analysis section 4.4 of the SI.

The noticeable difference between weekend and weekdays in the daily data resolution, coupled with energy grid data of a corresponding resolution, may prove to be an effective data-resolution compromise. The observed trends are apparent for all buildings: they all have substantially higher electricity usage on weekdays, followed by drops over the weekend and on holidays.

The impacts induced per kWh do not follow the same trend as the consumption. While there are falls in the average induced impact per kWh throughout a week, electricity consumption and observable impacts peak on weekdays. 
Although daily data resolution is not as detailed as hourly resolution, the fact that there are significant differences between the individual days, in terms of both consumption and induced impacts, stresses that daily data resolution still reveals factors that are not observable at lower data resolutions.

With daily data resolutions, the average impact potentials are again higher for the buildings in western Denmark: on average $34 \%$ at both the midpoint and endpoint levels.

\subsubsection{Monthly data resolutions}

Monthly data resolutions address the changes that occur over the scale of one month and can still reflect the aggregated differences throughout the year, but on a monthly basis.

Electricity usage analyses based on monthly data resolutions are similar to the impacts obtained from applying hourly and daily data resolutions. They show once again that electricity consumption by the western buildings induces greater impacts than consumption by the eastern buildings. The results for the western buildings are on average $35 \%$ higher on the midpoint level and $32 \%$ higher on the endpoint level. There is obviously a direct correlation between electricity demand and the induced impacts, since the western buildings on average perform worse than their eastern counterparts. Since data regarding specific building functions and occupancy rates were not available at the time of this study, it has not proved possible to identify the cause of these patterns of energy efficiency.

\subsubsection{Reference results}

The reference results give the environmental performance of the buildings, calculated using the reference procedure in the ecoinvent 3.3 database.

Ecoinvent's system modelling is non-dynamic, as it does not take into account the temporal variations in the grid data or electricity consumption data. Application of the ecoinvent data framework method entails invariant impact results for every $\mathrm{kWh}$ produced throughout the year and therefore does not take into account the variation in the electricity consumption of the different buildings at different time intervals (hourly/daily/monthly). 
Since the reference impact potentials per $\mathrm{kWh}$ for basic comparison are the same all year long, the differences in impacts between the eastern and western buildings are directly correlated with the energy results per $\mathrm{m}^{2}$, which are $33.4 \%$ higher on average for western buildings.

\subsubsection{Comparison}

The differences in impact results per $\mathrm{m}^{2}$ between the eastern and western buildings change to only a minor degree when we change the energy data resolution and base the calculation primarily on the consumption $/ \mathrm{m}^{2}$ of each building.

The value of the various data resolutions only becomes apparent when comparing the individual buildings and the variation in impacts resulting from the different data resolutions.

Since the energy data resolutions change in the comparisons, while building size, location and total energy consumption remain constant, any deviation in the environmental impact potential result solely from the changes in data resolution.

\subsection{Midpoints}

The difference ratios in terms of induced impacts observed among the different data resolutions stress that the hourly and daily data resolution levels, as seen in section 4.4 .3 of the SI, only yield minor differences. Table 3 presents the differences across all impact categories when the hourly resolution is compared to the other grids. The difference in induced impacts for hourly/daily resolutions across all impact categories is on average $<3 \%$, with the daily data resolution resulting in slightly higher impacts. The exception is building W4, for which the hourly data resolution impacts are $9.8 \%$ higher. Building W4 is equipped with solar panels that produce a significant amount of its electricity demand, as a result of which the higher data resolution influences the results for W4 more than it does for the other buildings. When comparing the hourly to the monthly data resolutions, the variations in the results become more distinct. The differences in average impacts are up to $7.8 \%$ higher when using monthly instead of hourly data resolutions. 
Table 3. Average total differences across all impact categories when compared to the impact potentials obtained by applying the hourly data resolution.

\begin{tabular}{cccc}
\hline Building & Hourly/daily resolutions & Hourly/monthly resolutions & Hourly/reference resolutions \\
\hline W1 & $1.8 \%$ & $5.4 \%$ & $158.8 \%$ \\
\hline W3 & $2.9 \%$ & $6.1 \%$ & $165.6 \%$ \\
\hline W4 & $9.8 \%$ & $7.8 \%$ & $134.3 \%$ \\
\hline W5 & $2.3 \%$ & $3.7 \%$ & $158.7 \%$ \\
\hline W6 & $1.8 \%$ & $3.7 \%$ & $157.8 \%$ \\
\hline W7 & $1.6 \%$ & $5.0 \%$ & $159.4 \%$ \\
\hline W8 & $1.6 \%$ & $5.2 \%$ & $160.3 \%$ \\
\hline W9 & $1.9 \%$ & $6.3 \%$ & $160.0 \%$ \\
\hline E1 & $1.3 \%$ & $3.5 \%$ & $187.9 \%$ \\
\hline E2 & $1.4 \%$ & $3.8 \%$ & $187.2 \%$ \\
\hline E3 & $1.5 \%$ & $2.9 \%$ & $187.1 \%$ \\
\hline E4 & $1.3 \%$ & $4.2 \%$ & $188.5 \%$ \\
\hline E5 & $1.5 \%$ & $4.0 \%$ & $188.2 \%$ \\
\hline E6 & $1.4 \%$ & $3.2 \%$ & $186.5 \%$ \\
\hline E7 & $1.3 \%$ & $3.6 \%$ & $187.4 \%$ \\
\hline E8 & $1.3 \%$ & $3.9 \%$ & $186.9 \%$ \\
\hline E9 & $1.5 \%$ & $3.9 \%$ & $190.9 \%$ \\
\hline
\end{tabular}

The results obtained by comparing the hourly data resolution system with the reference data resolutions reveals more substantial differences than the other comparisons. The impacts obtained by applying the reference data resolutions are significantly higher and range between 134.3 and $190.9 \%$. However, this difference is amplified by the four specific categories where the difference exceeds $400 \%$. Ignoring these four categories results in average differences of between $40 \%$ and $71 \%$, which the authors consider more reasonable.

The deviations presented in Table 4 show that, except for the occupation of agricultural land, all induced impacts are higher (in some cases over 600\%) when using the reference data resolutions. In particular, four specific categories show extreme differences between the two resolutions: ionizing radiation, freshwater ecotoxicity, marine ecotoxicity and water depletion. 
Table 4. Deviations in midpoint impact results per $\mathrm{m}^{2}$ averaged for all buildings, between reference data and hourly data resolution, for western and eastern Denmark.

\begin{tabular}{lll}
\hline Reference vs. hourly resolution & West & East \\
\hline Fossil depletion & $77.8 \%$ & $84.1 \%$ \\
\hline Marine eutrophication & $34.1 \%$ & $47.3 \%$ \\
\hline Terrestrial acidification & $56.0 \%$ & $45.2 \%$ \\
\hline lonizing radiation & $403.6 \%$ & $541.6 \%$ \\
\hline Freshwater ecotoxicity & $469.4 \%$ & $664.4 \%$ \\
\hline Photochemical oxidant formation & $32.4 \%$ & $33.3 \%$ \\
\hline Terrestrial ecotoxicity & $101.9 \%$ & $118.8 \%$ \\
\hline Marine ecotoxicity & $435.3 \%$ & $609.1 \%$ \\
\hline Climate Change & $84.6 \%$ & $82.6 \%$ \\
\hline Particulate matter formation & $48.7 \%$ & $41.6 \%$ \\
\hline Human toxicity & $50.5 \%$ & $73.6 \%$ \\
\hline Metal depletion & $120.9 \%$ & $188.7 \%$ \\
\hline Natural land transformation & $84.5 \%$ & $83.1 \%$ \\
\hline Urban land occupation & $15.7 \%$ & $1.8 \%$ \\
\hline Water depletion & $568.9 \%$ & $437.2 \%$ \\
\hline Freshwater eutrophication & $21.9 \%$ & $49.4 \%$ \\
\hline Ozone depletion & $82.9 \%$ & $87.3 \%$ \\
\hline Agricultural land occupation & $-24.9 \%$ & $-36.5 \%$ \\
\hline
\end{tabular}

These extreme variations are most likely due to certain energy production processes that are present or represented in the reference data resolutions but not present to the same extent in the hourly calculated energy grid compositions. We estimate that this pattern is caused by an over-represented reliance on imported electricity and coal- or waste-based electricity in the reference data resolutions. Occupation of agricultural land yields higher impacts when using the hourly data resolutions, most likely due to the amounts of biomass-based electricity being under-estimated when using reference data resolutions.

The differences between reference system and hourly data system already become evident in the calculation of the induced impacts per unit of electricity production: the reference system induces significantly higher impacts per kWh for all impact categories except the occupation of agricultural land. However, these differences in impact are amplified when coupled with the data for building electricity consumption, where the difference in data resolution amplifies the already substantial differences, this being observed for most 
impact categories. For instance, the difference when comparing hourly and reference data resolutions in terms of impacts per kWh produced on average amounts to $50.5 \%$ (west) and $73.6 \%$ (east) for human toxicity. However, these differences, which are expressed in terms of impacts per unit of energy consumed, amplify the differences to $58 \%$ (west) and $82 \%$ (east). This shows that the variation has its origin in the calculations of power grid composition, and that the difference is further amplified by the difference in data resolution, most likely because of the far from average grid composition observed during peak consumption in the seventeen buildings.

\subsection{Endpoints}

The endpoint scores for all buildings are presented as impact potentials per $\mathrm{m}^{2}$ in section 4 in the SI. As with the midpoint impact potentials, comparison of the results becomes clearer when using the relative comparisons based on percentage values.

Contrary to the midpoint impact comparison of hourly, daily and monthly data resolutions, the endpoint scores are consistently higher for the hourly resolutions across all categories and for all buildings. Once again, building W4 is an outlier due to its solar panels. For the remaining buildings, the hourly/daily comparisons show differences of up to $5 \%$, and of over $6 \%$ for the hourly/monthly comparison.

Comparison between the hourly and reference data resolutions yields differences in ecosystem impacts that are considerably lower than for human health and resources. Depending on the building, the impact potentials are either higher or lower. The results differ on average between 5\% (lower) and 8\% (higher). However, the impact potentials for the other two endpoint categories are substantially higher for hourly data when compared with the reference system: on average, $71 \%$ higher for human health and over $81 \%$ for resources. As with the midpoint impact potentials, the reference data resolutions yield notably higher endpoint scores when compared to any of the results from the other systems that apply dynamic data resolutions. 
In terms of the grid composition specific impacts, the data resolution dependency observed for the midpoints are repeated by the end-points. The agricultural land occupation at the midpoint level is regarded as an outlier that is lower for the reference system. Also, the ecosystem impact endpoint is the category least affected by the application of dynamic grid data. Both impacts and impact groups are to some degree dependent on the flows connected to the use of biomass in electricity production. The effect is therefore apparent for both midpoint and endpoint scores. 
Table 5. Total endpoint score comparison between the hourly grid resolutions and the daily/monthly grid resolutions, as well as the reference grid, for all buildings. Differences displayed in percentages

\begin{tabular}{|c|c|c|c|c|c|c|c|c|c|c|c|c|c|c|c|}
\hline \multirow{3}{*}{$\begin{array}{l}\text { Building } \\
\text { W1 }\end{array}$} & \multicolumn{5}{|c|}{$\begin{array}{l}\text { Hourly/daily } \\
\text { resolutions }\end{array}$} & \multicolumn{5}{|c|}{$\begin{array}{l}\text { Hourly/monthly } \\
\text { resolutions }\end{array}$} & \multicolumn{5}{|c|}{$\begin{array}{l}\text { Hourly/reference } \\
\text { resolutions }\end{array}$} \\
\hline & \multicolumn{2}{|c|}{ Ecosystems } & \multirow{2}{*}{$\begin{array}{l}\text { Human health } \\
-2.7 \%\end{array}$} & \multirow{2}{*}{$\begin{array}{c}\text { Resources } \\
-4.3 \%\end{array}$} & \multirow[t]{2}{*}{ Average } & \multicolumn{2}{|c|}{ Ecosystems } & \multirow{2}{*}{$\begin{array}{c}\text { Human health } \\
0.1 \%\end{array}$} & \multirow{2}{*}{$\begin{array}{l}\text { Resources } \\
-2.8 \%\end{array}$} & \multirow[t]{2}{*}{ Average } & \multicolumn{2}{|c|}{ Ecosystems } & \multirow{2}{*}{$\begin{array}{c}\text { Human health } \\
79.3 \%\end{array}$} & \multirow{2}{*}{$\begin{array}{c}\text { Resources } \\
52.5 \%\end{array}$} & \multirow[t]{2}{*}{ Averag } \\
\hline & $-5.2 \%$ & $-4.9 \%$ & & & & $-6.7 \%$ & $-1.9 \%$ & & & & $5.8 \%$ & $72.3 \%$ & & & \\
\hline W4 & $-15.6 \%$ & $-13.8 \%$ & $-12.4 \%$ & $-13.9 \%$ & & $-16.1 \%$ & $-12.5 \%$ & $-11.1 \%$ & $-13.2 \%$ & & $-10.6 \%$ & $48.4 \%$ & $54.5 \%$ & $30.8 \%$ & \\
\hline W5 & $-3.3 \%$ & $-2.8 \%$ & $-0.8 \%$ & $-2.3 \%$ & & $-4.2 \%$ & $-2.1 \%$ & $-0.1 \%$ & $-2.1 \%$ & & $7.4 \%$ & $71.1 \%$ & $78.1 \%$ & $52.2 \%$ & \\
\hline W6 & $-3.6 \%$ & $-3.5 \%$ & $-1.4 \%$ & $-2.8 \%$ & & $-4.7 \%$ & $-2.3 \%$ & $-0.3 \%$ & $-2.4 \%$ & & $8.3 \%$ & $72.1 \%$ & $79.0 \%$ & $53.1 \%$ & \\
\hline W8 & $-4.8 \%$ & $-4.3 \%$ & $-2.2 \%$ & $-3.7 \%$ & & $-6.0 \%$ & $-1.5 \%$ & $0.4 \%$ & $-2.4 \%$ & & $6.5 \%$ & $73.3 \%$ & $80.3 \%$ & $53.4 \%$ & \\
\hline W9 & $-5.1 \%$ & $-3.5 \%$ & $-1.6 \%$ & $-3.4 \%$ & & $-6.6 \%$ & $-0.8 \%$ & $1.0 \%$ & $-2.1 \%$ & & $2.4 \%$ & $70.3 \%$ & $77.3 \%$ & $50.0 \%$ & \\
\hline E1 & $-3.0 \%$ & $-3.8 \%$ & $-2.4 \%$ & $-3.0 \%$ & & $-3.6 \%$ & $-2.2 \%$ & $-0.7 \%$ & $-2.2 \%$ & & $-1.7 \%$ & $73.9 \%$ & $87.9 \%$ & $53.4 \%$ & \\
\hline E2 & $-3.0 \%$ & $-3.8 \%$ & $-2.4 \%$ & $-3.0 \%$ & & $-4.7 \%$ & $-2.6 \%$ & $-1.1 \%$ & $-2.8 \%$ & & $-2.2 \%$ & $73.7 \%$ & $87.7 \%$ & $53.1 \%$ & \\
\hline E3 & $-2.6 \%$ & $-3.5 \%$ & $-2.2 \%$ & $-2.8 \%$ & & $-2.9 \%$ & $-2.3 \%$ & $-0.9 \%$ & $-2.0 \%$ & & $-1.2 \%$ & $73.8 \%$ & $87.7 \%$ & $53.5 \%$ & \\
\hline E4 & $-2.9 \%$ & $-4.0 \%$ & $-2.7 \%$ & $-3.2 \%$ & & $-4.2 \%$ & $-1.9 \%$ & $-0.4 \%$ & $-2.1 \%$ & & $-3.5 \%$ & $73.0 \%$ & $87.0 \%$ & $52.2 \%$ & \\
\hline E5 & $-3.0 \%$ & $-3.6 \%$ & $-2.2 \%$ & $-2.9 \%$ & & $-3.8 \%$ & $-1.8 \%$ & $-0.4 \%$ & $-2.0 \%$ & & $-4.7 \%$ & $70.8 \%$ & $84.8 \%$ & $50.3 \%$ & \\
\hline E7 & $-3.1 \%$ & $-3.9 \%$ & $-2.5 \%$ & $-3.2 \%$ & & $-3.9 \%$ & $-2.3 \%$ & $-0.8 \%$ & $-2.4 \%$ & & $-2.7 \%$ & $72.8 \%$ & $86.8 \%$ & $52.3 \%$ & \\
\hline E8 & $-2.9 \%$ & $-3.8 \%$ & $-2.4 \%$ & $-3.0 \%$ & & $-3.8 \%$ & $-1.9 \%$ & $-0.5 \%$ & $-2.1 \%$ & & $-5.3 \%$ & $69.9 \%$ & $83.9 \%$ & $49.5 \%$ & \\
\hline E9 & $-2.8 \%$ & $-3.6 \%$ & $-2.1 \%$ & $-2.8 \%$ & & $-3.5 \%$ & $-1.8 \%$ & $-0.3 \%$ & $-1.9 \%$ & & $0.2 \%$ & $77.1 \%$ & $91.2 \%$ & $56.2 \%$ & \\
\hline
\end{tabular}




\section{Discussion}

\subsection{Reference data resolution}

One of the focus points of this study is the comparison between the induced impact per kWh consumed when calculated by relying on the reference process found in the ecoinvent database and that found the measured electricity production data provided by Energinet for electricity and natural gas.

The two ways of calculating energy consumption-induced impacts differ in two major ways: first, in the energy sources covered by the reference data set that are absent when calculating the impacts from the observed and measured data; and secondly, in the temporal dynamics of the data.

While the major contributing form of electricity production is the same both in this study and in the database, that in the ecoinvent database: market for electricity, low voltage / $D K$, includes several inputs that are not present in the electricity production recorded in 2017, such as hydro-power, or the inclusion of the transmission network. This is a major source of disparity between the two methods of calculation, without it being clear which is the most accurate.

The second major difference is in the respective timeframes covered by the two methods. The ecoinvent reference database from openLCA was more than six years old (from 2012) at the time of our study, that is, five years older than the energy data used in the study (from 2017). Given the ways in which Denmark's energy grid has developed in the past six years in shifting towards more sustainable electricity production, the age of the reference process found in the ecoinvent database justifies the results obtained by using dynamic data.

Furthermore, the reference process for electricity production does not take into account the variations in the electricity grid that occur throughout the year. As the results from the energy grid indicate, there are notable changes in the impacts per $\mathrm{kWh}$ consumed depending on the time of year the electricity is produced, and the lack of temporal dynamics in the reference process is a major source of inaccuracy. 


\subsection{The complexity of energy data for buildings}

From the analysis of the data for building energy consumption, it has become apparent that the key component when comparing the environmental performance of the buildings is the performance indicator "energy consumption/building area". The differences in their impact potentials are directly correlated with the difference in energy consumption/building area.

A more accurate comparison between the buildings would require more complex data on them with regard to their functions and occupancy rates. The functions of each building vary, as can be observed from the daily electricity consumption data, where some buildings have a clear reduction during holidays, while others do not.

While our study focuses on the importance of temporal variations in energy consumption data for office buildings in Denmark, Roux et al. (2016) have conducted a similar study of a single-family house in France. Their results show that the impacts could differ by up to $40 \%$ depending on the temporal variations in the data. Our findings, combined with these earlier findings by Roux et al., highlight the necessity of increased temporal variation being incorporated into LCA, but they also emphasise that the results of dynamic LCA are context-dependent. This means that parameters such as building location (country/region), building functionality (residential/non-residential), occupancy rate (area/person) and energy composition should be addressed in any dynamic LCA approach.

Among the factors that contribute to the demand for energy and that play a role in the EBP of office buildings are the number of occupants, the hours of work and activities that take place outside the regular business hours, but these factors are not reflected in our analysis, which focuses solely on gross energy consumption. Should such temporal data become more available for future studies, more suitable comparisons of the environmental performances of these buildings might be possible, especially since some trends in comparisons, such as building age - as illustrated in this study - proved inconclusive. Appropriate comparisons might be made of environmental performance per occupant of a given building at any given 
time, or of the performance both during and outside of business hours, to determine which office buildings could be optimized with regard to their baseline operational energy consumption.

\section{Conclusion}

The composition of the Danish electricity grid comprises numerous sources whose relative contributions to the sum change over time. Assessing these dynamic data patterns and their implications for the environment in this study has proved to have a great influence on the impact potentials of electricity production, as well as the environmental performance of the buildings supplied by this grid.

The energy grid analysis shows that the data resolution (month/day/hour) for electricity production is important, as it directly influences the environmental impacts arising from electricity production. Our study also shows that, even without changing the building area or total electricity demand, the data resolutions changed the overall results. However, the differences between the results were not always substantial enough to justify the increased volumes of data and the time required to perform highly detailed analyses. For the midpoint characterization, the daily resolutions provided results very similar to those of the hourly resolutions, and, given the fact that the former require 24 times more data points than the daily data, the daily data resolutions are the most reasonable solution to recommend. The endpoint scores proved to be another story, as every increment in data resolution provided significant changes in results. As such the choice of data resolution will impact on the results for any increment used.

In almost all scenarios, the impact potentials calculated from the electricity production data collected differ greatly from the impact potentials calculated from the ecoinvent database. Nonetheless, the applied reference process is based on data that are five years older than the research data used in the study, while the Danish electricity grid data shows that the composition of the energy grid has changed greatly over the same period. The results show substantial deviation across all impact categories between the different electricity grids used, while methodological choices may to a degree influence this deviation. The analysis of 
the yearly development of the Danish electric grid showed substantial changes in the composition of the grid, which the reference process does not account for.

The analysis of the composition of the electric grid throughout the year shows that renewable energy sources dramatically reduce the environmental impact per kWh, but that they are still unreliable in respect of their contributions to the grid. Given the results of this study, a dynamic inventory modelling approach would always be recommended, but in cases where sufficient quantities and quality of data are not assured, a compromise could be achieved by creating building type-specific electrical grid processes in databases such as ecoinvent. These processes could be representative of different building functions such as residential, commercial or other and could correspond to a grid and electricity consumption profile that portrays more accurately the impacts of the grid during the operating and non-operating hours of various building types. The dynamic high-resolution data are obviously significantly more accurate and have proved to be greatly influential on environmental performance during the buildings' use stages. The future development of dynamic electrical grid modelling practices will provide real-time assessments of the energy performance of buildings once such data become available in real time. This will allow buildings to become reactive in terms of their electricity consumption by allocating less essential electricity-consuming processes to times when the environmental footprint of the grid composition is more favourable. 


\section{References}

[1] S. Hildebrandt, "Bæredygtig global udvikling". Jurist- og $\varnothing$ konomforbundets Forlag, ISBN 9788757436440, pp. 185-212, 2016.

[2] Institute for Planning, Aalborg University, "IDAs Energivision 2050 - sammenfatning," Aalborg University, pp. 1-24, 2015.

[3] K. N. Brejnrod, P. Kalbar, S. Petersen, and M. Birkved, "The absolute environmental performance of buildings," Build. Environ., vol. 119, pp. 87-98, 2017.

[4] Danish Energy Agency, "Monthly and annual energy statistics," Foreløbig energistatistik 2017, 2018. [Online]. Available: https://ens.dk/service/statistik-data-noegletal-og-kort/maanedlig-og-aarligenergistatistik [Accessed: 24-Aug-2018].

[5] R. M. Cuéllar-Franca and A. Azapagic, "Environmental impacts of the UK residential sector: Life cycle assessment of houses," Build. Environ., vol. 54, pp. 86-99, 2012.

[6] H. Birgisdóttir, F. N. Rasmussen, and D. B. R. Institute, "Introduction to LCA of Buildings," Danish Transp. \& Construction Agency, 2009.

[7] CEN, BS EN 15978:2011 "Sustainability of construction works - assessment of environmental performance of buildings. Calculation method" 2011.

[8] E. Maslesa, P. A. Jensen, and M. Birkved, "Indicators for quantifying environmental building performance: A systematic literature review," J. Build. Eng., vol. 19, no. March, pp. 552-560, 2018.

[9] R. Gyllenram, "Making Sustainability Activities a Key to Your Success - From Compliance Making Sustainability Activities a Key to Your Success From Compliance to Commitment 1 Introduction," Nord. Steel Constr. Conf. 2015, no. September, 2015.

[10] A. Vilches, A. Garcia-Martinez, and B. Sanchez-Montañes, "Life cycle assessment (LCA) of building refurbishment: A literature review," Energy Build., vol. 135, pp. 286-301, 2017.

[11] C. Roux, P. Schalbart, E. Assoumou, and B. Peuportier, "Integrating climate change and energy mix scenarios in LCA of buildings and districts," Appl. Energy, vol. 184, pp. 619-629, 2016.

[12] J. L. Sohn, P. P. Kalbar, and M. Birkved, "Life cycle based dynamic assessment coupled with multiple criteria decision analysis: A case study of determining an optimal building insulation level," J. Clean. Prod., vol. 162, pp. 449-457, 2017.

[13] W. O. Collinge et al., "Enabling dynamic life cycle assessment of buildings with wireless sensor networks," Sustain. Syst. Technol. (ISSST), 2011 IEEE Int. Symp., pp. 1-6, 2011.

[14] D. Beloin-Saint-Pierre, A. Levasseur, A. Pinsonnault, M. Margni, and I. Blanc, "How Can Temporal Considerations Open New Opportunities for LCA Industry Applications?," 6th Int. Conf. Life Cycle Manag., pp. 4, 2013.

[15] S. Su, X. Li, Y. Zhu, and B. Lin, "Dynamic LCA framework for environmental impact assessment of buildings," Energy Build., vol. 149, pp. 310-320, 2017.

[16] C. K. Anand and B. Amor, "Recent developments, future challenges and new research directions in LCA of buildings: A critical review," Renew. Sustain. Energy Rev., vol. 67, pp. 408-416, 2017. 
[17] C. Roux, P. Schalbart, and B. Peuportier, "Accounting for temporal variation of electricity production and consumption in the LCA of an energy-efficient house," J. Clean. Prod., vol. 113, pp. 532-540, 2016.

[18] A. Levasseur, P. Lesage, and M. Margni, "Dynamic LCA and its application to global warming impact assessment," Time, vol. 44, no. 8, pp. 3169-3174, 2010.

[19] W. O. Collinge, A. E. Landis, A. K. Jones, L. A. Schaefer, and M. M. Bilec, "Dynamic life cycle assessment: Framework and application to an institutional building," Int. J. Life Cycle Assess., vol. 18, no. 3, pp. 538-552, 2013.

[20] W. O. Collinge, A. E. Landis, A. K. Jones, L. A. Schaefer, and M. M. Bilec, "Integrating indoor environmental quality metrics in a dynamic life cycle assessment framework for buildings," IEEE Int. Symp. Sustain. Syst. Technol., 2012.

[21] E. S. Nwe, A. Adhitya, I. Halim, and R. Srinivasan, "Green Supply Chain Design and Operation by Integrating LCA and Dynamic Simulation," vol. 28, pp. 109-114, 2010.

[22] A. H. Shimako, L. Tiruta-Barna, A. B. Bisinella de Faria, A. Ahmadi, and M. Spérandio, "Sensitivity analysis of temporal parameters in a dynamic LCA framework," Sci. Total Environ., vol. 624, pp. 1250-1262, 2018.

[23] B. M. Zimmermann, H. Dura, M. J. Baumann, and M. R. Weil, "Prospective time-resolved LCA of fully electric supercap vehicles in Germany," Integr. Environ. Assess. Manag., vol. 11, no. 3, pp. 425-434, 2015.

[24] J. Kraus and P. Stepan, "Optimal Data Compression Techniques for Smart Grid and Power Quality Trend Data," IEEE, 15th International Conference on Harmonics and Quality of Power, pp. 707-712, 2012.

[25] Energinet, "Electricity Balance," 2017. [Online]. Available: https://www.energidataservice.dk/dataset/electricitybalance [Accessed: 20-Aug-2018].

[26] R. S. Jorge and E. G. Hertwich, "Grid infrastructure for renewable power in Europe: The environmental cost," Energy Environ. Bringing together Econ. Eng., vol. 69, no. 0, pp. 760-768, 2014.

[27] A. Gargiulo, P. Girardi, and A. Temporelli, "LCA of electricity networks: a review," Int. J. Life Cycle Assess., vol. 22, no. 10, pp. 1502-1513, 2017.

[28] S. Soimakallio, J. Kiviluoma, and L. Saikku, "The complexity and challenges of determining GHG (greenhouse gas) emissions from grid electricity consumption and conservation in LCA (life cycle assessment) - A methodological review," Energy, vol. 36, no. 12, pp. 6705-6713, 2011.

[29] Danish Energy Agency, "Energy Statistics," 2018. Available: https://ens.dk/en/our-services/statisticsdata-key-figures-and-energy-maps/annual-and-monthly-statistics [Accessed: 21-Aug-2018]. .

[30] GreenDelta, “openLCA 1.7.2," 2018. [Online]. Available: https://www.greendelta.com/project/collaboration-server/ [Accessed: 21-Aug-2018].

[31] Ecoinvent, "ecoinvent database," 2018. [Online]. Available: https://www.ecoinvent.org/database/ecoinvent-34/ecoinvent-34.html [Accessed: 21-Aug-2018].

[32] National Institute for Public Health and the Environment - the Netherlands, "ReCiPe," 2016. [Online]. Available: https://www.rivm.nl/en/About_RIVM/Organisation [Accessed: 21-Aug-2018]. 